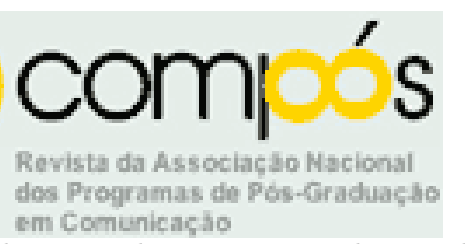

Este artigo foi publicado na edição 1, em dezembro de 2004, da revista eletrônica e-compós: http://www.compos.org.br/e-compos

\title{
JORNALISMO E REPRESENTAÇÕES SOCIAIS: ALGUMAS CONSIDERAÇÕES
}

Prof. Dr. Alfredo Eurico Vizeu Pereira Junior Departamento de Comunicação da UFPE

\section{INTRODUÇÃO}

O jornalismo, em particular, o televisivo é hoje a grande Praça Pública do País. A ágora eletrônica. Com certeza muito diferente da Praça de Discussões da Grécia antiga. Nela alguém era considerado cidadão não apenas quando se sentavam na ágora, um lugar de debates, mas quando lançava a mão da palavra da palavra apresentado seu projeto de como pensava que a cidade devesse ser organizada e governada. Essa é a verdadeira Praça Pública, a verdadeira participação.

A Praça Pública que tratamos aqui é do espaço público midiatizado através do qual a televisão, os rádios e os jornais contribuem diariamente para a construção do real. Para a maioria das pessoas, especialmente num País como o nosso no qual a primeira e muitas vezes a única informação disponível é aquela transmitida pela televisão, o campo midiático ocupa um espaço central na divulgação dos grandes temas nacionais no campo da economia, da política e da cultura.

Dentro desse contexto, entendemos que a mídia, pela disposição e incidência de suas notícias, desempenha uma importante função no sentido de tornar público os temas sobre os quais o público falará e discutirá. A hipótese do 
“agendamento" sustenta que as pessoas agendam seus assuntos e suas conversas em função do que a mídia veicula (McCOMBS; SHAW; 1993).

Partindo-se do pressuposto de que a sociedade moderna é caracterizada pela natureza fragmentada da experiência (PRYSTHON, 2002), pela conseqüente multiplicidade de esferas de legitimidade e pela autonomia das suas dimensões, acreditamos que, no campo midiático, o jornalismo assume hoje um imprescindível papel de mediação, garantindo deste modo a constituição de um sentido comum e a indispensável coesão social. Como diz Verón (1995), a mídia informativa é o lugar onde as sociedades industriais produzem a nossa realidade.

Diante desse quadro consideramos o jornalismo um campo fundamental para compreendermos como a realidade é construída cotidianamente. Como observa Vilches a mídia é uma forma atual de contato com o mundo. O que ela nos oferece é o presente social. Sem ela, o presente social é pobre e fica reduzido à família, aos vizinhos, ao trabalho, ao entorno. O campo midiático, o jornalismo, nos oferta outro perspectiva: “Graças a mídia, vivemos no mundo e sabemos o que está se passando um pouco em todas as partes” (GOMIS, 1991, p. 14).

A nossa preocupação ao longo do texto é discutir o jornalismo, em especial, a notícia como um campo relevante na construção do presente social. Partimos do princípio que a notícia é resultado da atividade diária dos jornalistas que a partir da cultura profissional, da organização do trabalho, dos processos produtivos, dos códigos particulares (as regras de redação), da língua e das regras do campo das linguagens, no trabalho da enunciação, produzem discursos. A operação sobre os vários discursos resulta em construções que, no jargão jornalístico, são chamadas de notícias.

O nosso objetivo é buscar pistas sobre como se dá esse processo. A hipótese que levantamos é que na prática diária os jornalistas constroem representações da economia, da política e da cultura que contribuem fortemente para a construção do mundo pela sociedade. Para procurarmos entender esse processo propomos algumas reflexões sobre as relações entre o jornalismo e representações sociais. $\mathrm{Na}$ caminhada procuramos estabelecer conexões entre a mídia, o campo do jornalismo, as práticas e a cultura profissional e as representações sociais. 


\section{MÍDIA, JORNALISMO E CONSTRUÇÃO DA REALIDADE}

Consideramos que hoje ao tratarmos do espaço público necessariamente estamos falando de um espaço público midiatizado. Com o observa Mayo (2004,p.7) a realidade não se produz, mas se reflete ou se capta, em algum lugar do espaço social:

\footnotetext{
"só em tais termos tem sentido uma denominação como a de 'meios de comunicação', na medida em que os mesmos são dispositivos de aproximação da audiência dos fatos que, por diversos motivos, são inacessíveis no espaço e no tempo".
}

Para o autor, a realidade se produz de forma massiva e cotidianamente no âmbito da mídia e, de maneira hegemônica, na televisão. É através da mídia que entramos em contato com a última declaração do presidente da República, tomamos conhecimento do ocorre no que diz respeito à Previdência, ao saláriomínimo, ao imposto de renda, o emprego no País, as eleições, entre outros assuntos. Essas notícias de uma forma ou de outra vão ser interpretadas das mais diversas formas, servindo de um importante instrumento para a compreensão do mundo.

É no âmbito da sociologia do conhecimento que nos situamos ao discutir a realidade como uma construção social. Burke (2003) ao fazer um mapeamento da história social do conhecimento observa que a ênfase passou da aquisição e transmissão do conhecimento para a sua construção, produção ou mesmo manufatura, mudança que faz parte de ma inclinação pós-estruturalista ou pósmoderna na sociologia e outras disciplinas. Segundo o autor, há menos preocupação com a estrutura social e mais sobre indivíduos, sobre a linguagem e sobre práticas como a classificação e o experimento. Há menos ênfase na economia e mais na política do conhecimento.

Para fins deste trabalho, julgamos que os estudos desenvolvidos por Berger e Luckmann (1995), que tratam não somente da multiplicidade empírica do “conhecimento" nas sociedades humanas, mas também dos processos pelos quais qualquer corpo de "conhecimento" chega a ser estabelecido como realidade, aproximam-se mais do nosso objetivo que é de procurar entender como o 
jornalismo contribui para a construção da realidade social.

Berger e Luckmann (1995) entendem que vida cotidiana apresenta-se como uma realidade interpretada pelos homens e subjetivamente dotada de sentido para eles na medida em que forma um mundo coerente. O conhecimento do senso comum é o conhecimento que eu compartilho com os outros nas rotinas da vida cotidiana. Ou seja, a realidade da vida cotidiana é partilhada com os outros.

Essa realidade é apreendida num contínuo de tipificações, de enquadramentos do mundo, que vão se tornando mais anônimos à medida que se distanciam do "aqui e agora" da situação face a face. Nesse processo recorro um estoque social de conhecimento, a um acervo, que me fornece os esquemas tipificadores exigidos para as principais rotinas da vida, não somente as tipificações dos outros, mas também os enquadramentos de todas as espécies de acontecimentos e experiências, tanto sociais quanto naturais.

A atividade humana (BERGER, LUCKMANN, 1995) está sujeita ao hábito. Toda e qualquer ação freqüentemente repetida torna-se moldada em um padrão, que pode em seguida ser reproduzido com economia de esforço que apreendida pelo executante como tal padrão. O hábito, além disso, resulta que a ação em questão pode ser novamente executada no futuro da mesma maneira e com o mesmo esforço econômico.

Esses processos de formação de hábitos precedem toda a institucionalização. Empiricamente a parte mais importante da formação da atividade humana é coextensiva com a institucionalização desta última. A institucionalização acontece sempre que há um enquadramento recíproco de ações habituais por tipos de atores. Ou seja, qualquer uma dessas tipificações é uma instituição. Essas tipificações das ações habituais constituem as instituições que são sempre partilhadas. São acessíveis a todos os membros de um grupo social e a própria instituição tipifica os atores individuais assim como as ações individuais.

\section{O MUNDO DOS JORNALISTAS}

Os enquadramentos recíprocos das ações são construídos ao longo de uma história compartilhada. Em outras palavras, as instituições têm sempre uma 
história da qual são produtos. A relação entre o homem, produtor, e o mundo social, produto dele, é uma relação dialética, isto é, o homem (evidentemente não o homem isolado mas em coletividade) e seu mundo social atuam reciprocamente um sobre o outro. O produtor reage sobre o produto. Em resumo, a sociedade é um produto humano. A sociedade é uma realidade objetiva. O homem é um produto social (BERGER, LUCKMANN, 1995) .

Isso posto, consideramos que o campo midiático, em particular, o jornalismo televisivo ocupa um lugar central para buscarmos pistas de como o mundo é representado. Como observa Bourdieu (1997) o campo jornalístico baseia-se em um conjunto de pressupostos e de crenças partilhadas. Por exemplo, uma noção como rende bem na televisão, expressão comum usada no jargão dos jornalistas para dizer que uma fato tem boas imagens e pode entrar num telejornal, está no princípio da seleção que repórteres, redatores e editores operam na realidade social e também no conjunto das produções simbólicas.

"O campo jornalístico impõem sobre os diferentes campos de produção cultural um conjunto de efeitos que estão ligados, em sua forma e eficácia, à sua estrutura própria, isto é, à sua estrutura própria, isto é, à distribuição dos diferentes jornais e jornalistas segundo sua autonomia com relação às forças externas, as do mercado dos leitores $\mathrm{e}$ as do mercado os anunciantes"(BOURDIEU, 1997, p. 102).

Esse processo de construção do real no jornalismo vem sendo estudado por nós há dez anos (PEREIRA JUNIOR, 2001); (PEREIRA JUNIOR, 2002). Em 2004 começamos a desenvolver uma pesquisa (PEREIRA JR, 2004) que busca entender como nas suas práticas diárias os jornalistas constroem representações da cultura, da economia e da política. Sem dúvida, os caminhos para compreender como se dá esse processo pode ser estudado nas mais diversas perspectivas, os trabalhos realizados indicam-nos que deles conduz ao cotidiano dos jornalistas.

O mundo dos jornalistas tem merecido atenção dos pesquisadores. Travancas (1992) num estudo sobre a identidade do jornalista e em que ela está na ancorada oferece interessante pistas sobre o tema. Ampliando a análise da 
autora entendemos que os jornalistas não os únicos responsáveis pela produção da notícia. O complexo processo de produção da notícia é constituído por um grande número de atores, inclusive as próprias empresas de comunicação, que as investigações deste ou daquele momento é uma opção epistemológica do pesquisador.

Nos estudos que realizamos observamos que como a Travancas também identificou que é o fato de determinadas carreiras significarem bem mais do que uma atividade de emprego na vida de seus profissionais, gerando um envolvimento que resultará num estilo de vida e numa visão do de mundo específicos. É o caso do jornalista.

De certa forma é essa perspectiva que faz Zelizer (2000) a falar de uma comunidade interpretativa que de uma maneira geral trata a os jornalistas como uma comunidade "universal" que compartilha valores-notícia. A proposta de tribo jornalística, de Traquina (2002) não é muito diferente. Como o autor explica, o termo "tribo" transmite mais claramente a idéia dos membros dos membros desta comunidade interpretativa serem similares ao bricoleur do antropólogo Claude Levi-Strauss : “...isto é, o adepto do ‘faça-você-mesmo’ no desempenho de muitas tarefas, que usa a lógica das mãos e dos olhos - a lógica do concreto - no seu trabalho diário" (TRAQUINA, 2002). O autor conclui diz que o termo também transmite a idéia dos membros desta comunidade serem homens e mulheres de ação, marcados por uma atitude antiintelectualismo que é um "constrangimento cultural no mundo do jornalismo".

\section{AS PRÁTICAS JORNALÍSTICAS}

Concordamos com Zelizer e Traquina que os jornalistas constituem um grupo com realidades compartilhadas. No entanto, consideramos que os conceitos propostos por ambos não dão conta da complexidade do processo de produção da notícia apontando para uma certa homogeneidade de procedimentos e valores das comunidades dos jornalistas que ainda está a merecer novos estudos.Preferimos adotar provisoriamente o conceito de práticas jornalísticas da redação a partir do trabalho desenvolvido por Barros Filho e Martino (2003 ) sobre o habitus na comunicação. 
No que diz respeito a essas práticas nossos estudos tem como referencial teórico o campo que trata o jornalismo como um lugar de construção do real. Traquina (2001) argumenta que a teoria etnoconstrucionista defende que os jornalistas vivem sob a tirania do tempo. O desafio diário é ter que apresentar um produto finalizado quotidianamente, em particular na mídia tradicional: o jornal, o rádio e a tevê. Ele explica que o trabalho jornalístico diário é uma atividade prática orientada para o momento do fechamento (o deadline).

Para dar conta disso, as empresas do campo jornalístico são obrigadas a construir estratégias para fazer face ao desafio colocado pela dupla natureza da sua matéria-prima: 1) os fatos (a matéria-prima por excelência do jornalismo) podem surgir em qualquer parte; 2) os fatos podem surgir a qualquer momento; 3) face à imprevisibilidade as empresas jornalísticas precisam impor ordem no espaço e no tempo.

Vejamos agora dois conceitos que consideramos fundamentais na teoria etnoconstrucionista: a noticiabilidade e os valores-notícia. Eles estão relacionados de uma forma implícita numa idéia de construção da audiência. Ambos os conceitos foram trabalhados por Wolf (1994).

$\mathrm{Na}$ produção das notícias, temos de um lado a cultura profissional, entendida como um conjunto emaranhado de retóricas, astúcias táticas, códigos, estereótipos, tipificações, representações de papéis, rituais e convenções relativos às funções da mídia e dos jornalistas na sociedade, à concepção do produtonotícia e às modalidades que superintendem à sua confecção. Isso se traduz, pois, numa série de paradigmas e práticas profissionais dadas como naturais.

Por outro lado, temos restrições ligadas à organização do trabalho sobre as quais se criam convenções profissionais que contribuem para definir o que é notícia, contribuem ainda para legitimar o processo produtivo, desde o uso das fontes até a seleção dos acontecimentos. Estabelece-se, assim, um conjunto de critérios de relevância que definem a noticiabilidade de um fato, isto é, a possibilidade dele virar notícia.

Definida a noticiabilidade como o conjunto de elementos com os quais as empresas jornalísticas controlam e produzem a quantidade e o tipo de fatos, entre os quais vai selecionar as notícias, podemos definir os valores-notícia como um 
componente da noticiabilidade. A combinação deles vai ajudar o jornalista a definir quais os fatos que são suficientemente interessantes, significativos e relevantes para serem transformados em notícia.

Há que precisar que nem todos os valores-notícia são importantes de igual modo, nem todos são relevantes para cada notícia. Se isso acontecesse, os jornalistas não poderiam executar o seu trabalho porque não teriam tempo para considerar todos. Alguns são, praticamente, sempre relevantes, mas o número e a combinação pertinente para as notícias específicas variam.

No processo de produção da notícia, os valores-notícia operam no sentido de possibilitar uma certa organização no caos circundante, tornando assim possível a rotinização do trabalho. Isto é, são contextualizados nos procedimentos produtivos porque aí adquirem sentido, desempenhando a sua tarefa e se revestindo daquela aparência de bom-senso que os torna, aparentemente, elementos dados como certos, elementos naturalizados. É dentro desse contexto que os jornalistas contribuem no dia a dia para a construção do real, que estabelecem uma trama hegemônica de representações (GRAMSCI, 2000), (GRAMSCI, 1989).

Estabelecem uma série de critérios que constituem uma espécie de trama de fatos, uma representação hegemônica, do que deve ou não ser publicado, do que pode ou não entrar num jornal, num noticiário televisivo ou radiofônico, uma trama da faticidade (TUCHMAN, 1983).

Com o objetivo de buscar pistas para entender como os jornalistas constroem diariamente as representações da realidade tomamos por base a Teoria das Representações Sociais que surgiu com muita força nas Ciências Sociais a partir da Psicologia Social.

A teoria tem suas origens na sociologia e na antropologia. O conceito é citado pela primeira vez por Moscovici (1978) a partir da noção de Durkheim de representações coletivas:

"Em resumo, a sociedade não é de maneira alguma ser ilógico ou alógico, incoerente e caprichoso que muito se comprazem em ver nela. Muito pelo contrário, a consciência coletiva é a 
forma mais elevada da vida psíquica, já que é uma consciência das consciências” (DURKHEIM, 1996, p.494).

Para Moscovici (1978), as sociedades modernas são bem mais complexas. Dentro desse contexto, numa crítica às teorias positivistas e funcionalistas que já não davam conta de explicar a realidade em novas dimensões, ele propõe o conceito de representação social como um corpus organizado de conhecimentos e uma das atividades psíquicas "graças às quais os homens tornam inteligível a realidade física e social, inserem num grupo ou numa ligação cotidiana de trocas, e liberam os poderes de sua imaginação"(p.28).

\section{AS REPRESENTAÇÕES SOCIAIS: ANCORAGEM E OBJETIVAÇÃO}

Guareschi (2000, p.69-92), (GUARESCHI, 2004) observa que nas representações sociais estão presentes aspectos culturais, culturais e valorativos, ou seja, ideológicos. Essa interligação entre os elementos cognitivos, afetivos e de ação, além de serem centrais na teoria, representam um diferencial aos estudos cognitivos e discursivos para os quais a afetividade e a ação não chegam a despertar interesse.

Compartilhamos com os comentários de Oliveira e Werba (2002, p.104117) para quem as representações sociais buscam tornar o não familiar. Nesse sentido, dois processos básicos podem ser identificados como geradores de representações sociais: ancoragem e objetivação.

Grosso modo, a objetivação procura substanciar as idéias abstratas e converter os conceitos em categorias da linhagem para usarmos uma definição de Moscovici (1978, p.173). E, a ancoragem estabelece a firme inserção de uma ciência na hierarquia de valores e entre as operações realizadas pela sociedade.

Como lembra Moscovici (1978, p.174), a representação social surge onde há perigo para a identidade coletiva, quando a comunicação de conhecimentos submerge as regras que a sociedade se outorgou. A objetivação minimiza o problema ao integrar as teorias abstratas de um grupo especializado em elementos do meio ambiente geral. Da mesma maneira se dá com a ancoragem que transforma a ciência num saber útil para todos. 
Resumindo, a preocupação central da teoria das Representações Sociais tem como preocupação responder por que realmente as pessoas fazem, o que fazem? Por que as pessoas compram, o que compram, votam, se reúnem? Por que as pessoas desempenham determinadas ações e não outras? Segundo a teoria por detrás dessas ações, e fundamentando as razões pelas quais as pessoas tomam tais atitudes está uma representação do mundo que não é apenas racional, cognitiva, mas, muito mais do que isso é um conjunto amplo de sentidos criados e partilhados socialmente.

Ao final para procurar compreender como os estereótipos influenciam esse processo recorremos aos estudos de FERRÉS (1998) sobre os estereótipos. Segundo o autor, os estereótipos são representações sociais, institucionalizadas, reiteradas e reducionistas. Trata-se de representações porque pressupõem uma visão compartilhada que um coletivo possui sobre o outro. Reiteradas porque criadas com base numa repetição. A base de rigidez e de reiteração, os estereótipos acabam parecendo naturais; a sua finalidade é, na realidade, que não pareçam formas de discurso e sim formas de realidade. Finalmente, são reducionistas porque transformam uma realidade complexa em algo simples.

Por fim, consideramos que através da pesquisa estamos conseguindo caminhar no sentido de construir um modelo de estudo das representantes sociais e do jornalismo com um olhar do campo da comunicação. De uma maneira geral, as investigações que vem sendo realizadas tomam por base uma perspectiva de campos dos saber como a sociologia, a educação, a saúde, a antropologia e mesmo a psicologia deixando em aberto uma reflexão mais de fundo sobre as interações entre o jornalismo e as representações sociais (MOREIRA;JESUÍNO,2003).

Acreditamos que as possibilidades teóricas da aproximação entre jornalismo e representações sociais oferecem um amplo campo de estudos para buscarmos compreender como o campo jornalístico contribuir diariamente para a construção do real. E, em última análise esse campo constrói representações de uma sociedade - hábitos, costumes e comportamento -, da cultura e da política.

\section{REFERÊNCIAS BIBLIOGRÁFICAS}


BARROS FILHO, C. de., MARTINO, L. M. S. O habitus na comunicação. São Paulo, Paulus, 2003.p. 246.

BERGER, P., LUCKMANN, T. A construção social da realidade. 12ed. Petrópolis : Vozes, 1995. p.248.

BOURDIEU, P. Sobre a televisão. Rio de Janeiro : Jorge Zahar Editor, 1997. p.143.

DURKHEIM, É. As formas elementares da vida religiosa. São Paulo : Martins Fontes, 2003. p. 609.

GANS, H. J. Deciding what's new : a study of CBS Evening News, NBC Nightly News, Newsweek and Time . New York : Vintage Books, 1980. p. 393.

GOMIS, L. Teoría del periodismo : como se forma el presente. México : Paidós, 1991. p.212.

GRAMSCI, A. Cadernos do cárcere. Rio de Janeiro : Civilização Brasileira, 2000. p.420.

Os intelectuais e a organização da cultura. 7.ed. Rio de Janeiro : Civilização Brasileira, 1989. p.244.

GUARESCHI，P. Representações sociais. In: GUARESCHI, P. et al. O s construtores da informação : meios de comunicação, ideologia e ética. Petrópolis : Vozes, 2000. p.380. . Psicologia social crítica : como prática de libertação. Porto Alegre : Mundo Jovem, 2004. p.140.

FERRÉS, J. Televisão subliminar : socializando através de comunicações despercebidas. Porto Alegre : Artmed, 1998. p. 288.

MAYO, E, C. La producción mediática de la realidad. Laberinto : Madrid, 2004. p. 187.

McCOMBS, M. E, SHAW, D. L. The evolution pof agenda-setting : twenty five years in the markeplace ideas. Journal of Communcation, v. 43, n. 2, p.58-67,1993. p.58-67.

MOREIRA, A. S. P.,JESUÍNO, J. C.(orgs.). Representações sociais : teoria e prática. 2.ed. João Pessoa : Editora Universitária UFPB, 2003. p.536.

MOSCOVICI,S. A representação social da psicanálise. Rio de Janeiro : Zahar, 1978. 
OLIVEIRA, F. O. de, WERBA, G. C. Representações sociais. In: JACQUES, M. da G. C, SREY, M. N. et al. Psicologia social contemporânea. 6. ed. Petrópolis : Vozes,2002. p.262.

PEREIRA JUNIOR, A . E. V. Recife, 2003. 36 f. Rede Globo Nordeste : as representações sociais de Pernambuco nas notícias do Jornal Nacional. Trabalho de Pós-Graduação (Pesquisa PósCom/PIBIC) Programa de Pós-Graduação em Comunicação, Departamento de Comunicação Social, Universidade Federal de Pernambuco (UFPE).

A audiência presumida nas notícias no caso dos telejornais locais . Rio de Janeiro: UFRJ/ECO, 2002. p. 345. Tese ( Doutorado em Comunicação Social)

. Decidindo o que é notícia : os bastidores do telejornalismo. 1.ed. Porto Alegre :

PRYSTHON, A. Cosmopolitismos periféricos. Recife: Bagaço, 2002. p.165.

RODRIGUES, A. D. O discurso mediático. Lisboa, 1996, mimeo. p. 74.

BURKE, P. Uma história social do conhecimento : de Gutemberg a Diderot. Rio de Janeiro : Jorge Zahar Editor, 2003. p.241.

TRAQUINA, N. Uma comunidade interpretativa transnacional : a tribo jornalística. Media \& Jornalismo. Coimbra : Edições Minerva, no 1 , p. 45-64, outubro de 2002.

. Teorias das notícias : o estudo do jornalismo no século XX. In: O estudo do jornalismo no século XX. São Leopoldo : Editora da Unisinos, 2001. p. 220.

TRAVANCAS, I. S. O mundo dos jornalistas. São Paulo : Summus Editorial, 1993. p.114.

TUCHMAN, G. La producción de la noticia : estudio sobre la construcción de la realidad. Barcelona : Gili, 1983. p.291.

VERÓN, E. Construir el acontecimento. 2.ed. Barcelona : Gedisa, 1995. p. 201

VILLAFAÑÉ, J, BUSTAMANTE, E, PRADO, E. Fabricar noticias : las rutinas productivas en radio y television. Barcelona : Mitre, 1987. p.157.

WOLF, M . Teorias da comunicação. Lisboa : Presença, 1994. p. 247. 
ZELIZER, B. Os jornalistas enquanto comunidade interpretativa. Revista de Comunicação e Linguagens, Lisboa : CECL, $n^{0}$ 27, p. 33-61, Fevereiro de 2000. 